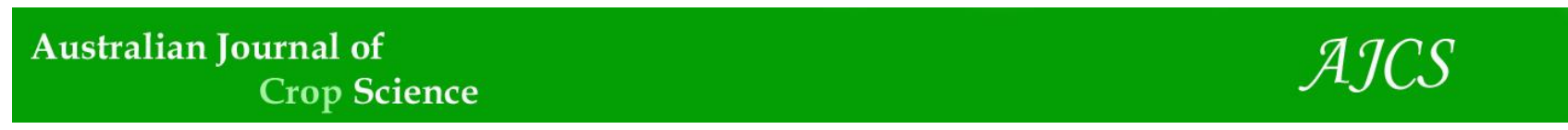

AJCS 11(11):1406-1410 (2017)

ISSN:1835-2707

doi: 10.21475/ajcs.17.11.11.pne484

\title{
Path analysis of grain yield associated characters in Brazilians wheat genotypes (Triticum aestivum L.)
}

\author{
Ivan Ricardo Carvalho', Maicon Nardino ${ }^{1}$, Diego Nicolau Follmann ${ }^{2}$, Gustavo Henrique Demari ${ }^{1}$, \\ Tiago Olivoto $^{2}$, Alan Junior Pelegrin ${ }^{1}$, Vinícius Jardel Szareski ${ }^{1}$, Mauricio Ferrari ${ }^{1}$, Tiago Corazza da \\ Rosa $^{1}$, Felipe Koch ${ }^{1}$, Geison Rodrigo Aisenberg ${ }^{1}$, Tiago Pedó ${ }^{1}$, Tiago Zanatta Aumonde ${ }^{1}$, Velci Queiróz \\ de Souza $^{3}$
}

${ }^{1}$ Federal University of Pelotas, CEP 96010-610, Capão do Leão, RS, Brazil
${ }^{2}$ Federal University of Santa MariaCampus de Frederico Westphalen, RS, Brazil
${ }^{3}$ Federal University of Pampa, Dom Pedrito, RS, Brazil

*Corresponding authors:carvalho.irc@gmail.com

\begin{abstract}
The aim of this study was to evaluate the phenotypic interrelation among agronomic characters associated with wheat grain yield of the main Brazilian cultivated genotypes through path analysis in two environments. The tests were conducted in Tenente Portela-RS and Braga-RS. The experimental design was randomized blocks arranged in factorial scheme, 2 locations $\times 17$ genotypes and 3 repetitions. The evaluated characters were plant height, main stem spike mass, tiller spikes mass, main stem spike grains number, tiller spikes grains number, main stem spike grains mass, tiller spikes grains mass, mass of a thousand grains and grain yield. Path analysis was performed for characters associated with grain yield. The results show that main stem spike grains mass, main stem spike grains number, and tiller spikes grains mass have direct effects on grain yield. Larger main stem spike grains mass, main stem spike grains number, and tiller spikes grains mass should be considered for achieving genotypes of high grain yield potential.
\end{abstract}

Keywords: Triticumaestivum, direct and indirect effects, yield component.

Abbreviations: PH_plant height; MSSM_main stem spike mass, TSM_tiller spikes mass; MSGN_main stem spike grains number;TSGN_tiller spike grains number; MSGM_main stem spike grains mass;TSGM_tiller spikes grains mass; MTG_mass of a thousand grains; GY_grain yield.

\section{Introduction}

The development of superior genotypes considers the genotype high yield potential associated to broad environmental adaptability and predictability to environmental conditions. Genetic breeding programs demand considerable labor, time and financial resources, mainly for wheat crop (Cruz and Carneiro, 2006). The researches intensification has generated improvement in wheat production nationally (Bissoto, 2004). The artificial selection strongly contributes with the steps of genetic breeding process and new genotypes development, where grain yield is the most aimed character. The grain yield has low heritability. It is necessary to understand contribution of yield components that directly or indirectly influence grain production (Vieira et al., 2007). The selection based on one or few characters has revealed itself inefficient (Cruzand Carneiro, 2006). Therefore, correlation coefficient estimates and path analysis contribute to plant breeding for comprehension of interrelations among agronomic characters and grain yield. Correlation is characterized as a method that describes the linear relation between two variables, where a variation in determined character results in another variation of the associated characters. Significant correlation coefficients are classified, through their magnitude, where a null correlation corresponds to $\mathrm{r}=0.00$, weak correlation from $r=0.00$ to $r=0.30$, mean correlation from $r=0.30$ to $r=0.60$, strong correlation from $r=0.60$ to $r=0.90$, very strong correlation from $r=0.90$ to $r=1$, and perfect correlation $r=1$ (Carvalho et al., 2004). The correlation fits in as an average of the intrinsic association of two characters in certain experimental condition. Therefore, it does not allow the cause and effect comprehension of secondary influence characters. Wright (1921) suggested a method to deploy the direct and indirect correlation effects, being grounded on a dependent variable analysis (y) and a set of explanatory variables, denominated as path analysis. According to Cruz and Carneiro (2006), this analysis allows evaluating the existence of relation between two characters, and whether the answer is due to other variable cause or effect. The path analysis is successfully employed on plant breeding, being useful for several crops, aiding the indirect selection of promising genotypes (Carvalho et al., 1999; Caierão et al., 2001; Coimbra et al., 2005). Thus, the aim of this study was to evaluate thebphenotypic interrelation among agronomic characters associated with wheat grain yield of the main cultivated Brazilians genotypes through path analysis.

\section{Results and discussion}

\section{Path analysis}

The direct and indirect effects on grain yield (GY) obtained through path analysis are shown in (Table 1$)$. The variable 
$\mathrm{PH}$ revealed direct effects but low and positive correlation coefficient related to grain yield, proving that plant height has inverse relation with crop productive potential, where height increases in wheat might be dispendious, compromising the utilization of assimilated products. Plant height $(\mathrm{PH})$ may be influenced by plants arrangement, light quality and availability, nutritional and hydric management and abiotic conditions (Teixeira and Rodrigues, 2003). Indirect effects are evidenced through the main stem spike grains number (MSGN), and main stem spike grain mass (MSGM) with elevated and positive correlation coefficient. The Pearson correlation evidences intermediary and positive coefficients related to the main character $(\mathrm{r}=0.45)$. The magnitude of this correlation is justified through indirect effects expressed by MSGN and MSGM characters. Correlation is a useful tool for genetic breeding; however, the wrong interpretation of its results may lead to misconceptions on selection strategy. Thus, high correlation coefficients between two variables might occur due to the indirect effect of a third variable or a group of characters (Nogueira et al., 2012). Selection of shorter plants may increase wheat productive potential. The results obtained are similar to those found by Kavalco et al. (2014), where mass of grains per spike and number of grains per spike is the main characters indicated for indirect selection of wheat populations, aiming grain yield increments. Direct effects of intermediary and positive magnitude on grain yield are observed for main stem spike mass (MSSM). It is observed as indirect high and positive coefficients through the characters MSGN and MSGM. Therefore, the magnitude increase of grains originated in the main stem spike contributes to increase of spike grains mass and plant grains mass, without interfering on mass of a thousand grains. The indirect selection through MSGM may be promising, where the correlation coefficient is higher than the residue. Tests conducted by Okuyama et al. (2004), reveal that wheat grain yield is closely related to aerial part biomass, number of spikes per square meter, and magnitude of grains per spike. The Pearson correlation is elevated and positive $(r=0.77)$, and it may be explained through the indirect effect of MSSM over crop yield. Results of Okuyama et al. (2004) affirmed that the relations between grain yield and its components in a simple correlation analysis are contrasting to those revealed on path analysis. Therefore, selection based on MSSM may promote the increment of grain yield through the characters MSGN and MSGM.

Wheat tillering is very important for genotypes productivity once they produce viable spikes, contributing for grain yield. Studies revealed that number of tillers is relevant for grain yield, being highly influenced by genotype features and environmental conditions (Kavalco et al., 2014). In a stress situation, the main stem development is prioritized (Elhani et al., 2007).

On this context, tiller spikes mass (TSM) evidences direct, low and positive effect on grain yield. It is observed that main stem spike grains mass (MSGM) and tiller spikes grain mass (TSGM) have indirect high and positive coefficients, contributing to the initial parameters. The total Pearson correlation $(\mathrm{r}=0.43)$ is intermediary and positive, which is explained through the indirect effects of MSGM and TSGM, increasing wheat grain yield.

The main stem spike grains number (MSGN) revealed direct effects with intermediary and positive correlation coefficient, proving the contribution of this character for crop productive potential. Indirect effects were observed through the variable main stem spike mass (MSSM), showing low and positive coefficients. Thus, main stem spike grain mass (MSGM) evidences high and positive effects on grain yield.
The selection of superior genotypes based on the increment of main stem spike grains number contributes to the grain yield. However, the main character magnitude evidences indirect contribution of spike mass and grains per spike. Similar results were observed by Vesohoski et al. (2011) andKavalco et al. (2014), where indirect selection for grain yield from number of grains per spike was characterized as the best strategy for achieving superior genotypes of wheat. The Pearson correlation $(\mathrm{r}=0.86)$ is elevated and positive, originated from direct and indirect effects of independent variables. The character tiller's spike grains number (TSGN) revealed direct effect with low and negative correlation coefficient for grain yield. Indirect effects with intermediary and positive coefficients were observed through the character main steam spike grains mass (MSGM) and number (MSGN). The tiller spike grains number is strongly influenced by the plant tiller magnitude, environmental features, characteristics of genotype, hydric and nutritional resources. Thereby, the character TSGN is influenced by many factors that interfere with the character magnitude. In conclusion, the selection based on this character is inefficient for increasing wheat grain yield. The Pearson correlation $(r=0.53)$ shows intermediary and positive values, which is attributed to direct and indirect effects of MSGN and MSGM. On the other hand, Vieira et al. (2007) revealed that number of grains per spike expresses superior direct effect to grain yield, when compared to the effects of other characters of agronomic interest. The main stem spike grains mass (MSGM) revealed direct effect with high and positive correlation coefficient to grain yield.

Martin et al. (2013) evidenced that selection through spike grains mass is efficient and brings more contribution to wheat productive potential. Indirect effects are observed through the characters main stem spike grains number (MSGN) and main stem spike grains mass (MSGM), with intermediary and positive correlation coefficient. The Pearson correlation $(r=0.85)$ is elevated and positive, justifying the importance of this character for wheat grain yield. Thus, selection of elevated MSGM individuals may be considered as main criteria for achieving promising genotypes. The character tiller spike grains mass (TSGM) evidences intermediary and positive direct effect. We observed indirect high and negative coefficients through plant height $(\mathrm{PH})$, intermediary and positive through main stem spike grains number (MSGN), high and positive through main stem spike grains mass (MSGM). Therefore, plants with elevated grains mass originated from viable tillers tend to produce plants with lower stature, increasing the main steam spike grains mass and number. The Pearson correlation $(r=0.66)$ for this trait is intermediary and positive, justifying both direct and indirect effects contribution to the grain yield.

The character mass of a thousand grains (MTG) is a yield component in wheat crop, but it reveals influence of genotype features, nutritional and hydric management (Gross et al., 2012). We observed low and positive direct effect of MTG on grain yield, and the total Pearson correlation $(r=0.12)$ is low and positive. These results are explained by biotic and abiotic influence on the character, and may be modified through adverse environmental conditions.

Gondim et al. (2008) and Vesohoski et al. (2011) revealed that mass of a thousand grains shows positive correlation with grain yield. However, the magnitude varies in response to environmental conditions. Studies of Cruz et al. (2004) explained that null or equal to zero correlation coefficients do not express absence of relation between variables, but the lack of linearity in the obtained data. 
Table 1. Direct and indirect effects of plant height (PH), main stem spike mass (MSSM), tiller spikes mass (TSM), main stem spike grains number (MSGN), tiller spike grains number (TSGN), main stem spike grains mass (MSGM), tiller spikes grains mass (TSGM), mass of a thousand grains (MTG) on grain yield (GY) in 17 Brazilian wheat genotypes.

\begin{tabular}{lcccccccc}
\hline \multirow{2}{*}{ Effects } & \multicolumn{9}{c}{ Explanatory variables } & \multicolumn{7}{c}{ MSGM } \\
\cline { 2 - 9 } & PH & MSSM & TSM & MSGN & TSGN & MSGM & TSG \\
\hline Direct over GY & -0.05 & 0.15 & 0.00 & 0.26 & -0.03 & 0.52 & 0.12 & 0.03 \\
Indirect PH & - & -0.03 & -0.02 & -0.035 & -0.03 & -0.02 & -0.31 & 0.00 \\
Indirect MSSM & 0.09 & - & 0,06 & 0.11 & 0.06 & 0.11 & 0.07 & 0.00 \\
Indirect TSM & 0.00 & 0.00 & - & 0.00 & 0.00 & 0.00 & 0.00 & 0.00 \\
Indirect MSGN & 0.15 & 0.19 & 0.07 & - & 0.16 & 0.22 & 0.13 & -0.03 \\
Indirect TSGN & -0.02 & -0.01 & -0.02 & -0.02 & - & -0.02 & -0.03 & 0.00 \\
Indirect MSGM & 0.21 & 0.38 & 0.22 & 0.43 & 0.28 & - & 0.35 & 0.07 \\
Indirect TSGM & 0.06 & 0.06 & 0.10 & 0.06 & 0.10 & 0.08 & - & 0.01 \\
Indirect MTG & -0.00 & 0.00 & 0.00 & -0.00 & -0.00 & 0.00 & 0.00 & - \\
Total (r) & 0.45 & 0.77 & 0.43 & 0.86 & 0.52 & 0.85 & 0.65 & 0.11 \\
\hline Coefficient of determination & & & & & 0.90 & & & \\
Effectof residual variable & & & & & & & & \\
\hline
\end{tabular}

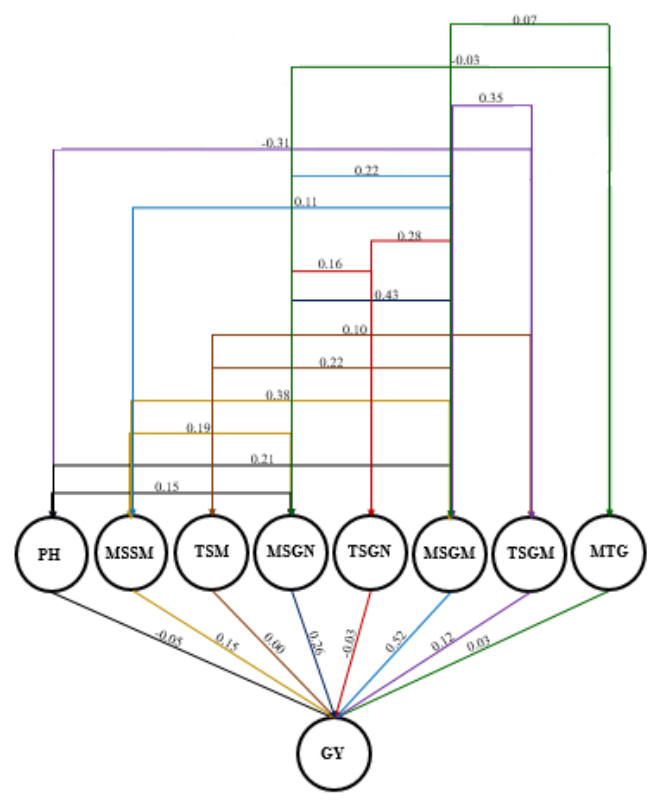

Fig 1. Direct and indirect effects of plant height (PH), main stem spike mass (MSSM), tiller spikes mass (TSM), main stem spike grains number (MSGN), tiller spike grains number (TSGN), main stem spike grains mass (MSGM), tiller spikes grains mass (TSGM), mass of a thousand grains (MTG) over grain yield (GY) on 17 Brazilian wheat genotypes.

The phenotypic correlation coefficients between characters associated to grain yield revealed high coefficient of determination (0.90) and low residual effect $(0.30)$, probing the interrelation between the studied characters. For selecting more productive genotypes in the experimental conditions, the increment of MSGN, MSGM, TSGM should be considered because they present direct and indirect relation in elevated magnitude with grain yield. Therefore, superior genotypes in main stem spike grains number, main stem spike grains mass, tiller spikes grains mass, as well as lower stature may express potential for selecting superior genotypes on the productive context.

The characters main stem spike grains mass, main stem spike grains number and tiller spikes grains mass revealed direct and significant effects on wheat grain yield for the evaluated genotypes in both experiment locations.

The achievement of elevated productive potential wheat genotypes in the experimental conditions of this study should consider bigger main stem spike grains mass, main stem spike grains number, and tiller spikes grains mass.

\section{Materials and Methods}

\section{Plant materials}

The experiment was conducted in two environments during the 2014 agricultural year. In Tenente Portela-RS, the geographic coordinates are $27^{\circ} 22^{\prime} 10,20^{\prime}$ 'S latitude, $53^{\circ} 45^{\prime} 23^{\prime \prime O}$ longitude, altitude of 420 meters, and the soil is classified as typical ferric oxisol. In Braga-RS, the geographic coordinates are $27^{\circ} 62^{\prime} 16^{\prime}$ 'S latitude, $53^{\circ} 73^{\prime} 55^{\prime} \mathrm{O}$ longitude, altitude of 430 meters, and the soil is classified as typical distroferricoxisol. According to Köppen, the weather is classified as Cfahumid subtropical (Motta,1953) for both locations.

\section{Experimental conduction}

The experimental design was randomized blocks arranged in a factorial scheme, composed by two locations $\times$ Brazilian 17 genotypes, in three repetitions. The Brazilians genotypes TBIOIguaçu, TBIOSeleto, TBIO Sinuelo, TBIOItaipu, 
TBIOAlvorada,

TBIOMestre

TBIOPioneiro, OR/TBIOQuartzo, TBIO Mirante, FUNDACEPRaízes, FUNDACEP 52, TEC Frontale,CD 1550, CD 1440, CD 123, CD 114 and CD 6219 used were in this study.

Each experimental unity was composed of 20 lanes spaced 0.17 meters, and 5 meters length. The plants density for all genotypes was 300 viable plants per square meter. No-tillage system was used in both locations, and fertilization was established according to the crop demand. Pests and diseases control occurred preventively. 10 central lines of each experimental unity were evaluated, excluding the first meter of each side to reduce the border effect. 10 plants were sampled to evaluate the characters of agronomic interest, obtaining the variable averages in each experimental unity.

\section{Traits measured}

The evaluated characters were: plant height $(\mathrm{PH})$, measured from the level of the soil to the plant top, excluding the awns. Results are expressed in cm. Main stem spike mass (MSSM): It was determined by the mass of each spike with the aid of digital scale, results expressed in g. Tiller spikes mass (TSM): It was determined by the mass of tiller spikes with the aid of digital scale, results expressed in g; Main stem spike grains number (MSGN): After individual threshing of each spike, the grain number in each spike was counted. Tiller spikes grains number (TSGN): After individual threshing of each tiller spike, every grain in the spike was counted. Main stem spike grains mass (MSGM): the main stem spike grains mass was measured through digital scale and results expressed in g. Tiller spikes grains mass (TSGM): the tiller spikes grains mass was measured through digital scale and results expressed in g. Mass of a thousand grains (MTG): Eight subsamples with one hundred grains were counted, with further adjustment for thousand grains weight and results expressed in g. Grain yield (GY): Obtained from the total grains mass per experimental unit with subsequent correction of grain humidity to $13 \%$, and effected the ratio of the parcel grains mass for the plants number. The grain yield per plant was adjusted to the population density, and results were expressed in $\mathrm{kg} \mathrm{ha}^{-1}$.

\section{Path and statistical analysis}

The data was submitted to variance analysis. Then, the phenotypic path analysis among agronomic characters was performed. For path analysis, the direct and indirect effects were estimated considering the following statistical model: $y$ $=p_{1} x_{1}+p_{2} x_{2}+\ldots+p_{n} x_{n}+p_{e} u$, where $y=$ grain yield dependent variable; $x_{1}, x_{2}, \ldots, x_{n}$ : explanatory variable; $p_{a}, p_{2}, \ldots p_{n}$ : Path coefficient.

The path coefficients were estimated according to the system of equations $X^{\prime} X \beta=X^{\prime} Y$ (LI, 1975), where:

$$
X^{\prime} Y=\left(\begin{array}{c}
r_{1 y} \\
r_{2 y} \\
\vdots \\
r_{n y}
\end{array}\right), X^{\prime} Y=\left(\begin{array}{cccc}
1 & r_{12} & \ldots & r_{1 n} \\
r_{12} & 1 & \ldots & r_{2 n} \\
\vdots & \vdots & \ddots & \vdots \\
r_{1 n} & r_{2 n} & \ldots & 1
\end{array}\right) \text { e } \beta=\left(\begin{array}{c}
p_{1} \\
p_{2} \\
\vdots \\
p_{n}
\end{array}\right)
$$

Thereby deploying the correlation between the dependent variable and the explanatory variable as shown below (CRUZ et al., 2004):

$$
\begin{gathered}
\mathrm{r}_{1 \mathrm{y}}=\mathrm{p}_{1}+\mathrm{p}_{2} \mathrm{r}_{12}+\ldots+\mathrm{p}_{\mathrm{n}} \mathrm{r}_{1 \mathrm{n}} \\
\mathrm{r}_{2 \mathrm{y}}=\mathrm{p}_{1} \mathrm{r}_{12}+\mathrm{p}_{2}+\ldots+\mathrm{p}_{\mathrm{n}} \mathrm{r}_{2 \mathrm{n}} \\
\ldots \quad \ldots \quad \ldots \\
\mathrm{r}_{\mathrm{ny}}=\mathrm{p}_{1} \mathrm{r}_{1 \mathrm{n}}+\mathrm{p}_{\mathrm{n} 2}+\ldots+\mathrm{p}_{\mathrm{n}}
\end{gathered}
$$

$$
\mathrm{r}_{\mathrm{iy}}=\mathrm{p}_{\mathrm{i}}+\sum_{\mathrm{j} \neq \mathrm{i}}^{\mathrm{n}} \mathrm{p}_{\mathrm{j}} \mathrm{r}_{\mathrm{ij}}
$$

Where:

$\mathrm{r}_{\mathrm{iy}}$ : correlation between the main variable selected by the researcher $(\mathrm{y})$ and the $\mathrm{i}^{\text {th }}$ explanatory variable:

$\mathrm{p}_{\mathrm{i}}$ : measure of the $\mathrm{i}$ variable direct effect on the main variable;

$\mathrm{p}_{\mathrm{i}} \mathrm{r}_{\mathrm{ij}}$ : : measure of the $\mathrm{i}$ variable indirect effect, through $\mathrm{j}$ variable, on the main variable.

As stated by Cruz et al. (2004), when the variable elimination is not desired for the researcher, it may be adopted procedures similar to ridge path analysis. In this methodology, it is assumed that in presence of multicollinearity, the least square estimator obtained of $X^{\prime} Y$ may be linked to very high variances. This adverse effect can be slightly modified in the normal equation system introducing the $\mathrm{K}$ constant on the diagonal matrix $X^{\prime} X$. Thus, the path coefficients were obtained through: $\left(\mathrm{X}^{\prime} \mathrm{X}+\mathrm{Kl}\right) \sigma=$ $\mathrm{X}^{\prime} \mathrm{Y}$;

$\sigma=\left[\begin{array}{c}p_{1}^{*} \\ p_{2}^{*} \\ \cdots \\ p_{n}^{*}\end{array}\right]$

By including the $\mathrm{K}$ constant, the decomposition of correlation between explanatory variables and basic variable is given by:

$$
\begin{aligned}
& \mathrm{r}_{1 \mathrm{y}}=(1+\mathrm{K}) \mathrm{p}_{1}^{*}+\mathrm{p}_{2}^{*} \mathrm{r}_{12}+\ldots+\mathrm{p}_{\mathrm{n}}^{*} \mathrm{r}_{1 \mathrm{n}} \\
& \mathrm{p}_{1}^{*} \mathrm{r}_{12}+(1+\mathrm{K}) \mathrm{p}_{2}^{*}+\ldots+\mathrm{p}_{\mathrm{n}}^{*} \mathrm{r}_{2 \mathrm{n}} \\
& \ldots \quad \ldots \quad \ldots \\
& \mathrm{r}_{\mathrm{ny}}=\mathrm{p}_{1}^{*} \mathrm{r}_{1 \mathrm{n}}+\mathrm{p}_{2}^{*} \mathrm{r}_{\mathrm{n} 2}+\ldots+(1+\mathrm{K}) \mathrm{p}_{\mathrm{n}}^{*}
\end{aligned}
$$

Then, we have:

$$
\mathrm{r}_{\mathrm{iy}}=(1+\mathrm{K}) \mathrm{p}_{1 \mathrm{i}}^{*}+\sum_{\mathrm{j} \neq \mathrm{i}}^{\mathrm{n}} \mathrm{p}_{\mathrm{j}}^{*} \mathrm{r}_{\mathrm{ij}}
$$

There were values from 0 to 1 for K. Cruz (1997) noted that between values, the lower value of the constant should be chosen, for which most of the path coefficients linked to the several characters are stabilized. The path diagram determination is given by:

$\mathrm{R}^{2}=\mathrm{p}_{1} \mathrm{r}_{1 \mathrm{y}}+\mathrm{p}_{2} \mathrm{r}_{2 \mathrm{y}}+\ldots+\mathrm{p}_{\mathrm{n}} \mathrm{r}_{\mathrm{ny}}$

The residual effect is estimated through:

$\rho_{\varepsilon=\sqrt{1-R^{2}}}$

Analysis were performed through the Genes statistic software (CRUZ, 2013).

\section{Acknowledgements}

The first author acknowledges a fellowship by Universidade Federal de Santa Maria Campus Frederico Westphalen (UFSM) Brazil, and Laboratório de Melhoramento Genético e Produção de Plantas (UFSM).

\section{References}

Bissoto V (2004) Some considerations about wheat crop.Southern Brazil wheat research commission meeting. Passo Fundo, Embrapatrigo.

Brasil Ministry of Agriculture, Livestock and Food supply. Volumetric weight additional determinations. Rules for seed analysis. Brasília. p.334.

Caierão E, CarvalhoFIF, Pacheco MT (2001) Indirect selection to increment grain yield in oats. Ciência Rural. 31(32): 231-236 
Carvalho CGP, Oliveira VR, Cruz CD (1999) Path analysis under multicollinearity in green pepper. Braz J Agric Res. 34(4): 603-613.

Carvalho FIF, Lorencerti C, Benin G (2004) Estimates and Implications of Correlation.Pelotas. Ed. Universitária da UFPEL, 142p.

Coimbra JLM, Benin G, Vieira EA (2005) Multicolinearity consequence on path analysis in canola. Ciência Rural. 35(2): 347-352.

Cruz CD, Regazzi AJ, Carneiro PCS (2004) Modelos biométricos aplicados ao melhoramento genético, Ed 3. Viçosa, 480p.

Cruz CD, Carneiro PCS (2006) Modelos biométricos aplicados ao melhoramento de plantas. Ed 2. Viçosa: UFV, $585 \mathrm{p}$.

Cruz CD (2013) Genes - a software package for analysis in experimental statistics and quantitative genetics. Acta Scientiarum. 35(3): 271-276.

Elhani S, Martos V, Rharrabti Y, Royo C, Garcia Del Moral LF (2007) Contribution of main stem and tillers to durum wheat (Triticumturgidum 1. Var. Durum) grain yield and its components grown in mediterranean environments. Field Crop Res. Amsterdam103(1): 25-35.

Gondim TCO, Rocha VS, Sediyama CS, Miranda GV (2008) Path analysis for yield components and agronomic traits of wheat under defoliation. Braz J Agric Res. 43(4): 487-493.

Gross TF, Dias AR, Kappes C, Schiebelbein M, Anselmo JL, Holanda HV (2012) Productive performance of wheat in different sowing methods and densities. Scientia Agrária Paranaensis. 11(4): 50-60.

Kavalco SAF, Figueiredo R, Groli EL, Zimmer CM, Baretta D, Tessmann EW, Júnior AMM, Oliveira AC (2014) Pathway analyses in wheat genotypes under waterlogging stress. Semina - Ciências Agrárias. 35(4): 1683-1696.

Li CC (1975) Path Analysis - A primer. 3.Ed. Pacific grove, box wood, $347 \mathrm{p}$.
Martin TN, Storck L, Benin G, Simionatto CC, Ortiz S, Bertoncelli P (2013) Importance of the relationship between characters in dualpurpose wheat in crop breeding. Biosci J. 29(6): 1932-1940.

Mota FS (1953) Rio Grande do Sul state climate study according to the w. Koeppen system. Agronomic J. 8 (193): 132-141

Nogueira APO, Sediyama T, Sousa LB, Hamawaki OT, Cruz CD, Pereira DG, Matsuo É (2012) Path analysis and correlations among traits in soybean grown in two dates sowing. Biosci J. 28(6): 877-888.

Okuyama LA, Fererizzi LC, Barbosa Neto JF (2004) Correlation and path analysis of yield and its components and plant traits in wheat. Ciência Rural, Santa Maria. 34(6): 1701-1708.

Tedesco MJ (2004) Manual de adubação e de calagem para os estados do Rio Grande do Sul e de Santa Catarina/Soil Science Brazilian Society. Soil Chemical and Fertility Comission. 10 Ed. Porto Alegre, 401 p.

Teixeira MCC, Rodrigues O (2003) Nitrogen fertilization, plants arrangement and growth reducer effect on lodging and barley characteristics.Passo Fundo: Embrapa Trigo, $16 \mathrm{p}$.

Vesohoski F, Marchioro VS, Franco FA, Cantelle A (2011) Components of grain yield in wheat and its direct and indirect effects on productivity. Revista Ceres. 58(3): 337 341

Vieira EA, Carvalho FIF, Oliveira AC, Martins LF, Benin G, Silva JAG, Coimbra J, Martins AF, CarvalhoMF, Ribeiro G (2007) Path analysis among primary and secondary yield components in wheat. Revista Brasileira de Agrociência. 13(2): $169-174$ 